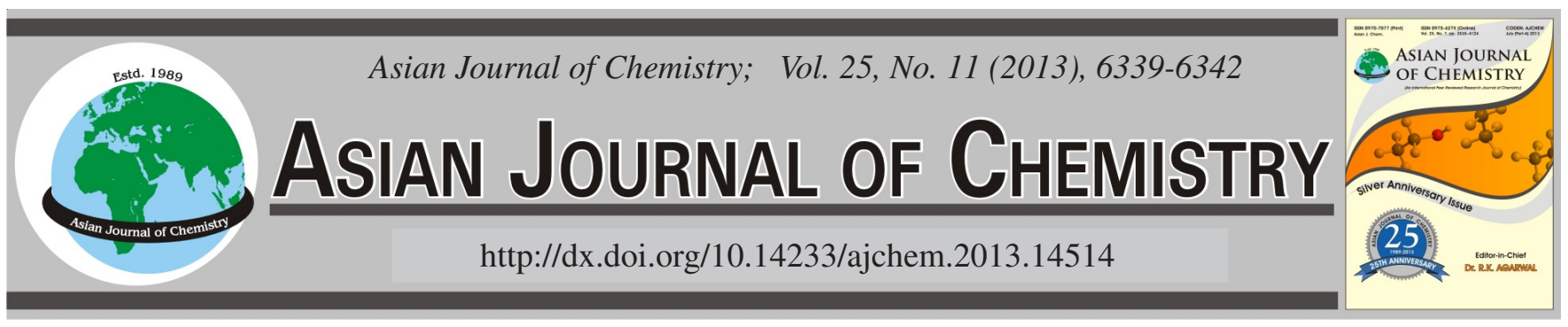

\title{
Sn/Nano-SiC Composite Electrodeposition Technology
}

\author{
Hongtao Chu ${ }^{1,2}$, Yue ZhaO ${ }^{2}$, Lieiang Su ${ }^{2}$, Jingiu Zhang ${ }^{1}$ and Maozhong An ${ }^{1, *}$
}

${ }^{1}$ State Key Laboratory of Advanced Welding and Joining, Harbin Institute of Technology, Harbin 150001, P.R. China

${ }^{2}$ College of Chemistry and Chemical Engineering of Qiqihar University, Qiqihar 161006, P.R. China

*Corresponding author: E-mail: mzan@ hit.edu.cn

(Received: 3 September 2012;

Accepted: 10 May 2013)

AJC-13467

\begin{abstract}
A Sn/nano-SiC composite electrodeposition technology was studied. The effects of electrodeposition behaviour were investigated by the concentration of main salt, the concentration of methylsulfonic acid, current density etc. The influence law of particles content in the solution on the particle content in $\mathrm{Sn} /$ nano-SiC composite coating was also studied. The results show that, when the concentration of $\mathrm{Sn}^{2+}$ was $0.21-0.24 \mathrm{~mol} / \mathrm{L}$, the concentration of methylsulfonic acid was $90-120 \mathrm{~g} / \mathrm{L}$, current density was $1.5-2.5 \mathrm{~A} / \mathrm{dm}^{2}$, there was a higher deposition rate in the electrodeposition process, current efficiency and throwing power were both above $90 \%$. The nano-SiC content in composite coating was increased with $\mathrm{SiC}$ content in bath increasing, when it was $5 \mathrm{~g} / \mathrm{L}, \mathrm{SiC}$ content in composite coating was highest.
\end{abstract}

Key Words: Tin, Nano-SiC, Composite electrodeposition, Deposition rate, Throwing power.

\section{INTRODUCTION}

The tin-lead alloy coating, which had good weldability and the ability of restraining the growth of the tin whisker, was widely used in the electronic components and semiconductor packaging. However, the tin-lead alloy coating was under restrictions because of negative effects of lead elements on the environment.

Now, as lead-free tin coatings $\mathrm{Sn}-\mathrm{Bi}, \mathrm{Sn}-\mathrm{Ag}, \mathrm{Sn}-\mathrm{Cu}$, $\mathrm{Sn}-\mathrm{Zn}$ binary alloy coatings and $\mathrm{Sn}-\mathrm{Ag}-\mathrm{Cu}$ ternary alloy coatings etc. were developmented ${ }^{1}$, but all these above couldn't really replace tin-lead coating.

The new technology for improving the coating performance was nano composite electrodeposition technology, which was to add the nanometer scale solid particles to the electroplating solution. It could be made solid particles and the substrate metal deposited in the substrate together through the electrical deposition method ${ }^{2}$. The nanoparticles such as $\mathrm{Al}_{2} \mathrm{O}_{3}{ }^{3}, \mathrm{La}_{2} \mathrm{O}_{3}{ }^{4}, \mathrm{SiC}^{5,6}, \mathrm{SiO}_{2}{ }^{7}$ and $\mathrm{ZrO}_{2}{ }^{8}$ could be added into the electroplating solution.

Research showed that, nanoparticles composite coating had a superior performance of wear resistance, reducing friction, high temperature resistance and corrosion resistance ${ }^{9}$. $\mathrm{Ni}-\mathrm{P}-\mathrm{TiO}_{2}$ nanocomposite coating was prepared by Khalifa et al. ${ }^{10}$, whose research investigated the effect of $\mathrm{TiO}_{2}$ content in the composite coating on coating performance, coming to the conclusion that the wear resistance, corrosion resistance of the coating strengthened with the increase of $\mathrm{TiO}_{2}$ content in composite. The same conclusion was obtained through the research on $\mathrm{Ni} / \mathrm{SiC}$ nanocomposite coating by Sohrabi et al. ${ }^{11}$.

Tin matrix nanoparticles composite coating kept characteristics of low melting point, good weldability, which could improve corrosion resistance and wear resistance and also restrain the growth of tin whisker. Therefore, it was expected to replace tin-lead alloy coatings, which has a broad prospect of application.

The SiC nanoparticles were added into the tin-plating solution and $\mathrm{Sn}-\mathrm{SiC}$ nanoparticles composite coating can be obtained by the electrical deposition method. Through the single factor test, the effects of $\mathrm{Sn}\left(\mathrm{CH}_{3} \mathrm{SO}_{3}\right)_{2}$ concentration, methylsulfonic acid concentration, current density and $\mathrm{SiC}$ concentration in plating solution on the coating composition, performance of solution are investigated.

\section{EXPERIMENTAL}

Copper matrix, which was steeped in $30 \% \mathrm{H}_{2} \mathrm{SO}_{4}$ and alkaline solution $\left(30 \mathrm{~g} / \mathrm{LNa}_{2} \mathrm{CO}_{3}-30 \mathrm{~g} / \mathrm{L} \mathrm{NaHCO}_{3}\right)$ in turn, was used for cathode and the pure tin was used as anode, respectively. To produce the composite coatings, $\mathrm{SiC}$ nanoparticles were added into plating solution for deposition of tin of methylsulfonic acid system.

Nanometer composite coating was prepared with the constant current during the process of electrodeposition. The composition of the plating solution and the electrodeposition parameters are summarized in Table-1. 


\begin{tabular}{|c|c|}
\hline \multicolumn{2}{|c|}{$\begin{array}{c}\text { TABLE-1 } \\
\text { PLATING SOLUTION COMPOSITION } \\
\text { AND DEPOSITION PARAMETERS }\end{array}$} \\
\hline Plating solution composition & Parameter range \\
\hline $\mathrm{Sn}\left(\mathrm{CH}_{3} \mathrm{SO}_{3}\right)_{2}$ (as metal) $\left(\mathrm{c} / \mathrm{g} \mathrm{L}^{-1}\right)$ & $16.5-47.2 \mathrm{~g} \mathrm{~L}^{-1}$ \\
\hline $\mathrm{CH}_{3} \mathrm{SO}_{3} \mathrm{H}(70 \%)\left(\mathrm{c} / \mathrm{g} \mathrm{L}^{-1}\right)$ & $10-120 \mathrm{~g} \mathrm{~L}^{-1}$ \\
\hline Nano-SiC $\left(\mathrm{c} / \mathrm{g} \mathrm{L}^{-1}\right)$ & $0.5-5 \mathrm{~g} \mathrm{~L}^{-1}$ \\
\hline Hydroquinone $\left(\mathrm{c} / \mathrm{g} \mathrm{L}^{-1}\right)$ & $2 \mathrm{~g} \mathrm{~L}^{-1}$ \\
\hline Brightener $\left(\mathrm{c} / \mathrm{mL} \mathrm{L}^{-1}\right)$ & $1 \mathrm{mLL}^{-1}$ \\
\hline Current density (I/A dm ${ }^{-2}$ ) & $1-4 \mathrm{~A} \mathrm{dm}^{-2}$ \\
\hline Electroplating time (t/min) & $20 \mathrm{~min}$ \\
\hline Anode & Tin plate \\
\hline Cathode & Copper foil \\
\hline Temperature $\mathrm{T}(\mathrm{K})$ & 298 \\
\hline
\end{tabular}

The throwing power of the tested plating solution through the method of far and near cathode (formula 1).

$$
\mathrm{T}=\frac{\mathrm{K}-\left(\frac{\mathrm{m}_{1}}{\mathrm{~m}_{2}}\right)}{\mathrm{K}+\left(\frac{\mathrm{m}_{1}}{\mathrm{~m}_{2}}\right)-2} \times 100 \%
$$

where $\mathrm{T}$ is throwing power; $\mathrm{K}$ is the ratio of the distance of far cathode to near cathode, which is 2 in the experiment; $m_{1}$ is weight increment of far cathode and $\mathrm{m}_{2}$ is weight increment of near cathode, respectively.

Cathodic current efficiency was calculated by the law of Faraday, which can be seen in formula 2.

$$
\eta=\frac{\mathrm{m}}{\mathrm{ItK}} \times 100 \%
$$

In the formula $2: \eta$ is current efficiency; $m$ is the quality of the actual precipitated material, I is the passing electric current, $\mathrm{A} ; \mathrm{t}$ is time of the passing current, $\mathrm{h} ; \mathrm{K}$ is electrochemical equivalent $\mathrm{g} /(\mathrm{A} \mathrm{h})$. Coating microstructure was observed by scanning electron microscope(SEM,S-4300, Hitachi).

\section{RESULTS AND DISCUSSION}

Effect of $\mathrm{Sn}\left(\mathrm{CH}_{3} \mathrm{SO}_{3}\right)_{2}$ concentration: The effects of $\mathrm{Sn}\left(\mathrm{CH}_{3} \mathrm{SO}_{3}\right)_{2}$ concentration on electrodeposition technology are shown in Fig. 1. As is shown in Fig. 1(a), $\mathrm{Sn}\left(\mathrm{CH}_{3} \mathrm{SO}_{3}\right)_{2}$ concentration has a marked effect on deposition rate. With the increase of the concentration of $\mathrm{Sn}\left(\mathrm{CH}_{3} \mathrm{SO}_{3}\right)_{2}$, the deposition rate of the coating promoted. When the concentration of $\mathrm{Sn}^{2+}$ was increased to more than $0.24 \mathrm{~mol} / \mathrm{L}$, deposition rate barely changed; the throwing power of the plating solution strengthened along with the increase of the concentration of $\mathrm{Sn}^{2+}$. When the concentration of $\mathrm{Sn}^{2+}$ reached $0.24 \mathrm{~mol} / \mathrm{L}$. As shown in Fig. 1(b), the throwing power of the plating solution was greater than $96 \%$. The change of the throwing power was tending to be gentle with further increasing the concentration of the $\mathrm{Sn}^{2+}$.

When the concentration of $\mathrm{Sn}^{2+}$ increased in a certain range, the amount of reducible ions near the cathode increased, the deposition potential of tin moved to positive direction and deposition rate promoted. However, with greater concentration of $\mathrm{Sn}^{2+}$, reaction rate of cathode was too fast. As a result, the reduction rate of $\mathrm{Sn}^{2+}$ was greater than dissolution rate of anode and the increasing tendency of the concentration of $\mathrm{Sn}^{2+}$
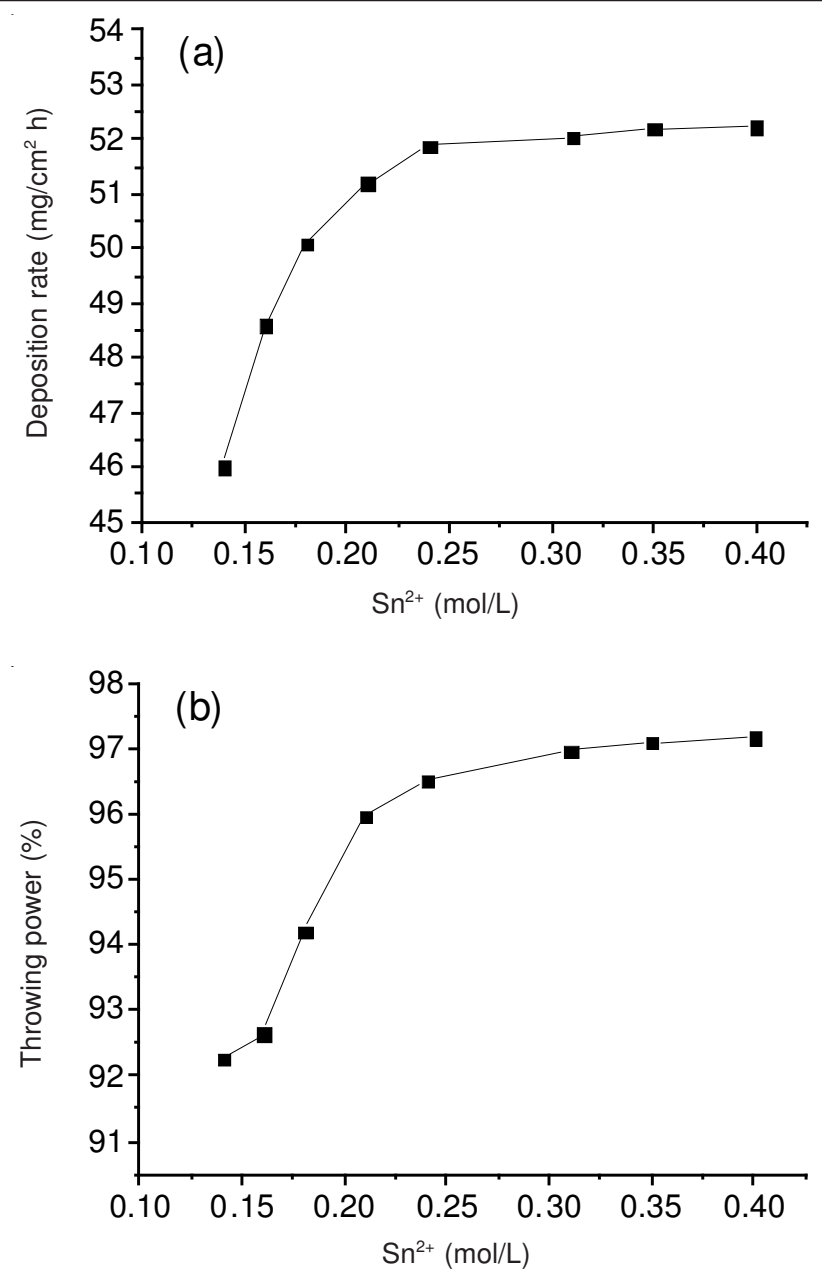

Fig. 1. Effect of $\mathrm{Sn}\left(\mathrm{CH}_{3} \mathrm{SO}_{3}\right)_{2}$ concentration on composite electrodeposition

near the cathode slowed down. At this time metal deposition rate was determined by ion diffusion rate and deposition rate was affected.

With greater concentration of $\mathrm{Sn}^{2+}$, the polarization of cathode lowered and the throwing power was limited. Meanwhile, the interaction between ions led to the change of electrical conductivity of solution and uneven distribution of the current density on cathode surface, which was one of the reasons to slowly strengthen the throwing power. Therefore, the concentration of $\mathrm{Sn}^{2+}$ should be in the range of $0.21-0.24 \mathrm{~mol} / \mathrm{L}$.

Effect of the concentration of methylsulfonic acid: The effect of the methylsulfonic acid concentration on deposition rate and throwing power in the technology of composite electrodeposition can be observed in Fig. 2.

Fig. 2(a) showed that with increasing the concentration of methylsulfonic acid, deposition rate of coating increased, which varied from $43.3 \mathrm{mg} / \mathrm{m}^{3} \mathrm{~h}$ to approximately $50 \mathrm{mg} / \mathrm{m}^{3}$ $\mathrm{h}$. Deposition rate was substantially unchanged when the concentration of methylsulfonic acid was greater than $90 \mathrm{~g} / \mathrm{L}$. It can be seen from the Fig. 2(b) that the throwing power of the plating solution decreased along with the increase of the concentration of methylsulfonic acid, reducing from 100 to $96.2 \%$. However, in the experimental conditions, the throwing power of plating solution was all greater than $96 \%$, which indicated that the concentration of methylsulfonic acid had little effect on throwing power. 

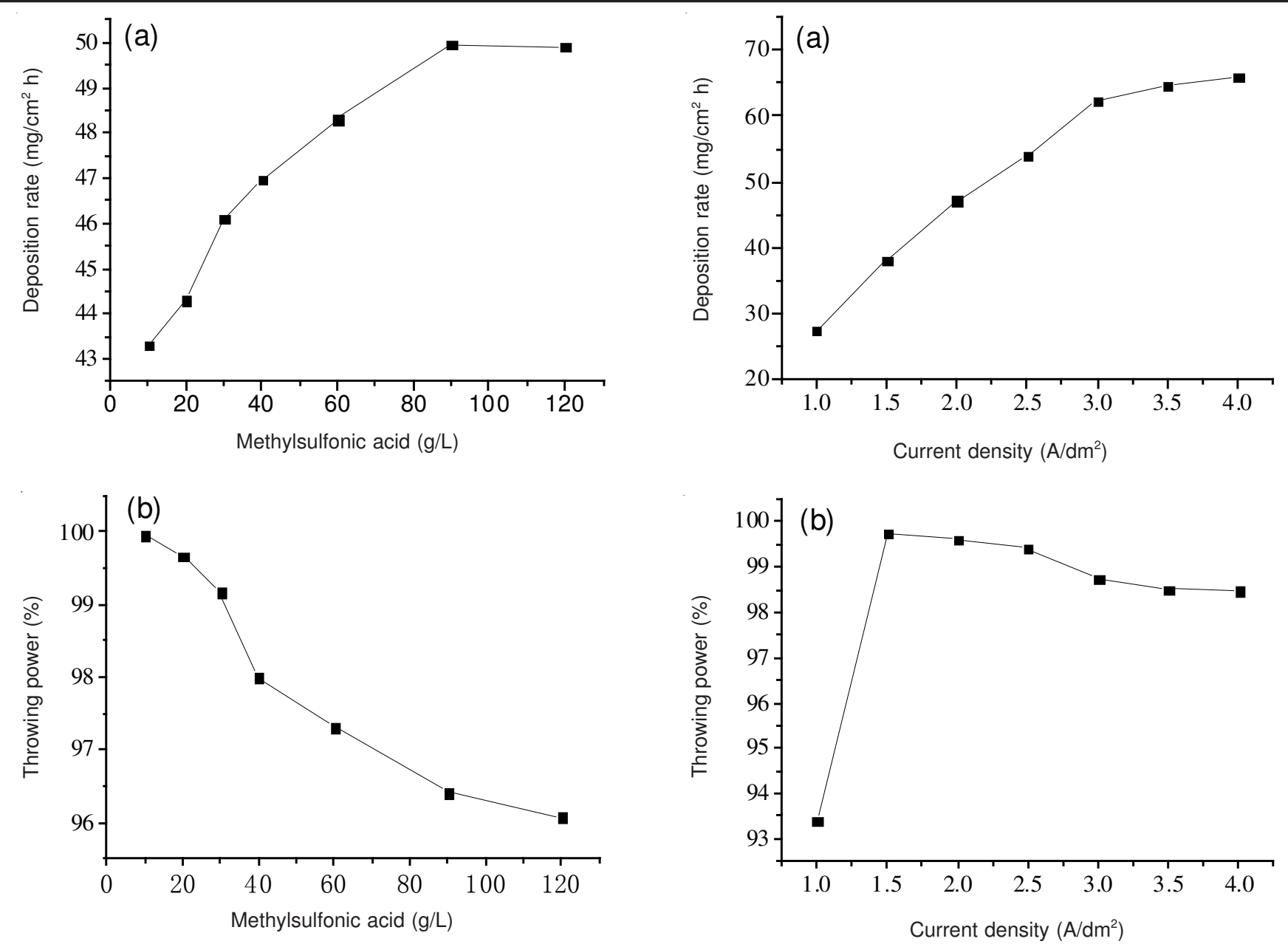

Fig. 2. Effect of the concentration of methylsulfonic acid on composite electrodeposition

The deposition rate and throwing power of plating solution were affected by electrical conductivity of the plating solution. Methylsulfonic acid played a role in conduction and complexing in the plating solution, which improved the stability and throwing power of the plating solution, respectively. The electrical conductivity of the plating solution became poor and deposition rate of coating reduced when the concentration of methylsulfonic acid was too low.

The concentration of methylsulfonic acid had little effect on throwing power of the plating solution. Therefore, the content of methylsulfonic acid should be below $120 \mathrm{~g} / \mathrm{L}$ in the experiment.

Effect of current density on composite coating: The effect of current density on deposition rate and throwing power is shown in Fig. 3.

Fig. 3(a) presents that deposition rate of composite coating increased with the increasing of current density. Deposition rate almost increased linearly when current density was at 1-3 $\mathrm{A} / \mathrm{dm}^{2}$, however, deposition rate changed slowly when current density was greater than $3 \mathrm{~A} / \mathrm{dm}^{2}$. It could be observed from the curves in Fig. 3(b) that the throwing power of plating solution showed improving tendency with the increase of current density. When the current density was at $2 \mathrm{~A} / \mathrm{dm}^{2}$, the throwing power reached maximum and then slowed down. The throwing power could maintain a higher rate, under current density of $1.5-2.5 \mathrm{~A} / \mathrm{dm}^{2}$.

Fig. 3. Effect of current density on composite coating

Increase in current density quickened the reduction speed of cation and determined metal electrical deposition rate. When the time of electrodeposition was fixed, the coating thickness in one area of cathode was positive proportional to the product of current density and current efficiency, that is, as the current density increased, lead to the metal electrical deposition rate accelerated. However, the exaggerated current density resulted in fast deposition rate of cathode $\mathrm{Sn}^{2+}$, which was faster than the dissolution rate of anode tin, resulting in low concentration of $\mathrm{Sn}^{2+}$ in plating solution. At this time, with the occurrence of side effects, current efficiency was affected and thus, deposition rate increased slowly. Therefore, the current density should be in the range of $1.5-2.5 \mathrm{~A} / \mathrm{dm}^{2}$.

Effect of current density on throwing power is given in Fig. 3, which shows plating solution has a higher throwing power. The throwing power was $99.8 \%$ under current density of $1.5 \mathrm{~A} / \mathrm{dm}^{2}$, therefore, current density has minor effect on throwing power.

It is already known that the throwing power of the plating solution could be expressed by even distribution degree of plating thickness in plating area, coating thickness was proportional to the product of current density and current efficiency. $\mathrm{Sn}^{2+}$ which in methylsulfonic acid system had the characteristic of metal complex, cathode polarization curve of metal complex ion had a larger polarization degree when it retuned to metal in the cathodic, it could make current density distribution of 
different parts of the cathodic more uniformly. Moreover, current density of complex plating solution was often reduced with increasing of current efficiency, which would make the distribution of metal coating on cathode surface uniform and hardly affected by current density.

Effect of SiC concentration on composite coating: Fig. 4 shows that $\mathrm{SiC}$ content in coating increased with increasing of $\mathrm{SiC}$ concentration in the plating solution. The change of $\mathrm{SiC}$ content in coating was little when $\mathrm{SiC}$ concentration was greater than $4 \mathrm{~g} / \mathrm{L}$.

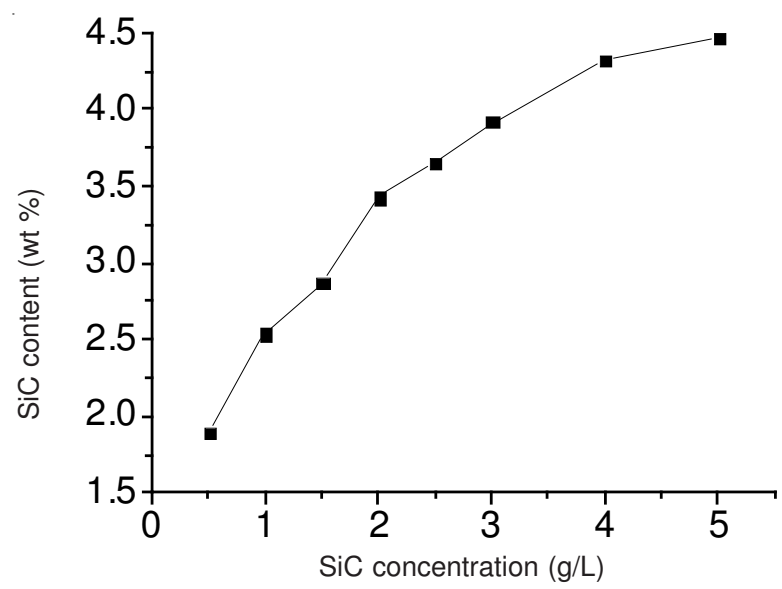

Fig. 4. Effect of nano-SiC concentration on $\mathrm{SiC}$ content in composite coating

As nanoparticles concentration in plating solution increased, under the agitation, nanoparticles were input into the cathode and the number of collisions and adsorption on the cathode increased and the possibility of $\mathrm{SiC}$ being covered and encased by tin deposited was promoted. However, as $\mathrm{SiC}$ concentration in the plating solution was increased, the chances of mutual collision between particles in the plating solution and cathode surface promoted, resulting in agglomerate and sediment of nanoparticles in plating solution, which had an effect on adsorption of the particles on cathode surface, therefore, SiC content in coating was limited.

The addition of nano $\mathrm{SiC}$ had a certain effect on electrical conductivity of the plating solution and further made it possible for current density distribution on cathode surface to become uneven and there was resistance for adsorption and reduction of cation at the cathode, as a result, throwing power and the deposition rate all reduced with the increasing of $\mathrm{SiC}$ concentration.

SEM images of the prepared Sn-nano SiC composite coating are given in Fig. 5. The conditions for the preparation of coating are the following: $47.2 \mathrm{~g} \mathrm{~L}^{-1} \mathrm{Sn}, 120 \mathrm{~g} \mathrm{~L}^{-1} \mathrm{CH}_{3} \mathrm{SO}_{3} \mathrm{H}$, $2 \mathrm{~g} \mathrm{~L}^{-1}$ nano-SiC, $2 \mathrm{~g} \mathrm{~L}^{-1}$ hydroquinone, $1 \mathrm{~mL} \mathrm{~L}^{-1}$ brightener, 4 $\mathrm{A} \mathrm{dm}^{-2}$ current density, temperature $298 \mathrm{~K}$. As shown in Fig. 5 one can see that the flat and ordered surface has relatively homogenous $\mathrm{SiC}$ grains.

\section{Conclusion}

In this paper, the composite electrodeposition behaviour of $\mathrm{Sn}-\mathrm{SiC}$ nanoparticles was discussed, effects of concentration of $\mathrm{Sn}\left(\mathrm{CH}_{3} \mathrm{SO}_{3}\right)_{2}$ and methylsulfonic acid and current density and nano-SiC concentration in plating solution on composite

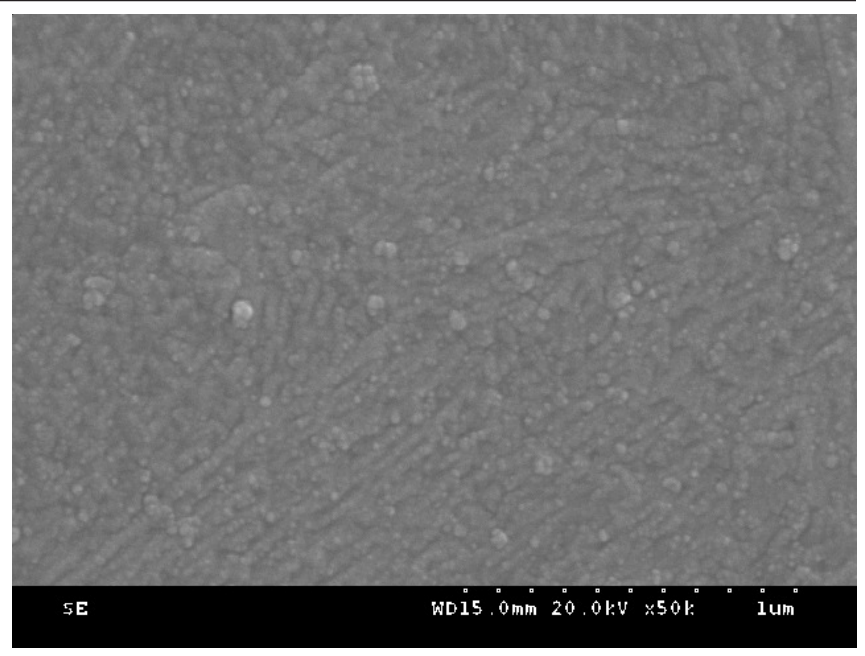

Fig. 5. SEM image of Sn-nano SiC composite coating

electrodeposition were investigated. Finally, conclusions are summarized as follows. With the increasing of concentration of methylsulfonic acid, the deposition rate of coating increases and the throwing power reduces, therefore, the concentration of methylsulfonic acid should be less than $120 \mathrm{~g} / \mathrm{L}$ and the throwing power should be greater than $96 \%$. The deposition rate of coating and throwing power increases with increasing of $\mathrm{Sn}^{2+}$ concentration; both are close to maximum when the concentration reaches $0.24 \mathrm{~mol} / \mathrm{L}$. Deposition rate almost increases linearly when current density is at $1-3 \mathrm{~A} / \mathrm{dm}^{2}$. The deposition rate slowly changes as current density is greater than $3 \mathrm{~A} / \mathrm{dm}^{2}$. The throwing power of solution reaches maximum when current density is at $2 \mathrm{~A} / \mathrm{dm}^{2}$. When the current density is in the range of $1.5-2.5 \mathrm{~A} / \mathrm{dm}^{2}$, plating solution could maintain a higher throwing power and greater deposition rate. $\mathrm{SiC}$ content in coating increased with increasing of $\mathrm{SiC}$ concentration in the plating solution. The change of $\mathrm{SiC}$ content in coating was little when $\mathrm{SiC}$ concentration was greater than $4 \mathrm{~g} / \mathrm{L}$.

\section{ACKNOWLEDGEMENTS}

This work was financially supported by the Education Department of Heilongjiang Province (No. 12521607), Technology Bureau of Qiqihar city of China(No. GYGG2010-06-1) and State Key Laboratory of Advanced Welding and Joining of Harbin Institute of Technology.

\section{REFERENCES}

1. J.Q. Zhang, M.Z. An, L.M. Chang and G.Y. Liu, Electrochim. Acta, 53, 2637 (2008).

2. K. Vathsala and T.V. Venkatesha, Appl. Surf. Sci., 257, 8929 (2011).

3. H.Y. Zheng and M.Z. An, J. Alloy. Comp., 459, 548 (2008).

4. Y.J. Xue, J.S. Li, W. Ma and M.-D. Duan, J. Mater. Sci., 41, 1781 (2006).

5. C. Zanella, M. Lekka and P.L. Bonora, Surf. Eng., 26, 511 (2010).

6. H.K. Lee, H.Y. Lee and J.M. Jeon, Met. Mater. Int., 14, 599 (2008).

7. H. Li, Y.Z. Wan, H. Liang, X.L. Li, Y. Huang and F. He, Appl. Surf. Sci., 256, 1614 (2009).

8. F.Y. Hou, W. Wang and H.T. Guo, Appl. Surf. Sci., 252, 3812 (2006).

9. M.-C. Chou, M.-D. Ger, S.-T. Ke, Y.-R. Huang and S.-T. Wu, Mater. Chem. Phys., 92, 146 (2005)

10. O.R.M. Khalifa, E. Abd El-Wahab and A.H. Tilp, Aust. J. Basic Appl. Sci., 5, 136 (2011).

11. A. Sohrabi, A. Dolati, M. Ghorbani, M.R. Barati and P. Stroeve, J. Phys. Chem.C, 116, 4105 (2012). 